by Danser in 1929, is useful because it can be fairly precisely defined, and is of a size comparable with the genus or subgenus. In Primula section Vernales, in Epil,bium section Chamoenerion, in Viola sections Nomimium, Dischidium, Chamoemelanium and Melanium, and in Poeonia, sections Moutan and Pceon, the comparium agrees well with the subgenus, section or subsection, and, where it disagrees, it provides useful suggestions for taxonomic revision. On the other hand, it is useless in genera such as Lathyrus, in which attempts to obtain interspecific hybrids have failed. It is interesting to note that in some families, for example, the Gramineæ, a single comparium may comprise many genera, such as Lolium-Festuca, and Triticum-Aegilops-AgropyronSecale-Elymus.

In order to analyse relationships within or between comparia, it was suggested that variation in what may be called seed compatibility, that is, the ability to form hybrid embryo, seed and seedling, could be used. Examples were given from the genus Viola at the sectional-level, and from Primula, section Vernales, at the specific-level. In the latter, evidence from both seed compatibility and hybrid fertility agrees in placing $P$. elatior closer to $P$. vulgaris than to $P$. veris. Application of this criterion to outbreeding diploid groups (gradual ecospecies) similar to the Vernales, for example, portions of the genera Rhododendron, Lolium, Quercus and Epilobium, were suggested. It was pointed out, however, that the hypothesis on which this application is based, namely, that degree of seed compatibility is proportional to taxonomic relationship, is clearly incorrect where the relation between diploid and tetraploid species is concermed. Here, analysis shows that comparable pairs of closely allied diploid and tetraploid species may vary enormously in seed compatibility. Thus, they may be completely intercompatible, as in Viola riviniana $(n=20) \times V$. reichenbachiana $(n=10)$, completely incompatible, as in Galeopsis tetrahit $(n=16)$ $\times G$. speciosa $(n=8)$ or, most commonly, as in Nasturtium microphyllum $(n=32) \times N$. officinale $(n=16)$, partially compatible.

In the general discussion which followed, Prof. Jenkin described some interesting results on seed compatibility in Lolium, and Dr. Turrill briefly reported some unpublished work of Mr. E M. MarsdenJones on Anagallis. The numerous colour forms of $A$. arvensis are all intercompatible and interfertile, but only a single one, out of more than thirty that are known, can be crossed with the related species A. femina. The reasons for this remarkable limitation of compatibility are as yet unknown.

D. H. Valentine

\section{CHEMISTRY OF THE CELL AND ITS NUCLEUS}

A

DISCUSSION on "The Chemistry of the Cell with Special Reference to the Nucleus", arranged by Section K (Botany) of the British Association at the Birmingham meeting, took place before a large audience on September 1 under the chairmanship of Prof. K. Mather.

Prof. M. Stacey (University of Birmingham) opened the discussion with a paper on the chemical composition of some cell nucleoproteins. He dealt first with the chemistry of deoxypentose nucleic acids and pentosenucleic acids, indicating that these must now be regarded as two distinct groups of nucleic acid, with quite marked differences in physical and chemical structures between products from different cells. Although the deoxypentose type is found mainly in nucleal structures and the pentose type mainly in cytoplasmic material, it is becoming evident that at different stages of cell-growth-especially in bacteria-there is a good deal of overlap in the location of the two groups of nucleic acid. The nucleic acids are found in firm combination with various types of protein, and methods for their separation. were outlined. The basic proteins in chromosomes are more complex than was thought by earlier investigators. The present position was then outlined of the magnesium ribonucleoprotein which forms the dye-retaining part of the surface structure of Gram-positive micro-organisms, and the new observation was made that only a small part of the ribonucleic acid of various cells is bound in the Gram complex. The behaviour of the nucleal proteins under the influence of cell 'autolytic' enzymes, especially the nucleases, was also discussed.

Dr. W. G. Overend dealt with work at Birmingham on the fundamental chemistry of the Feulgen and Dische reactions for cell nucleal material. He explained the need for knowing what takes place during cytological staining practice, particularly in regard to the nucleal components. The Dische reaction is primarily concerned with the deoxyribose in the chromosome nucleic acid, and it is seen as a blue stain when diphenylamine is added to the cellular material previously treated briefly with acetic and sulphuric acids. Studies on a wide variety of unusual carbohydrates, using spectrographic techniques, show that it is given by 2-deoxy pentoses and by furfuryl alcohol. These under acid conditions are finally converted into lævulic acid, which gives no colour with the reagent. It was shown that an intermediate substance in the conversion, namely, $\omega$-hydroxylævulic aldehyde, is the actual compound giving the dye with diphenylamine. Other compounds such as deoxyxyloses, which can be converted into this aldehyde, can give the Dische diphenylamine reaction, which is therefore relatively non-specific, and caution must be used in interpreting the results of the test. Protein breakdown products also influence the amount of colour produced.

The Feulgen reaction, which has been so valuable in locating nucleal structures, consists in the action of Schiff's aldehyde reagent on acid-treated cells to give a magenta colour. It depends on the fact that in deoxypentosenucleic acid the deoxy sugar occurs in the furanose or 5-atom ring form, and under acid conditions the ring opens readily to give a relatively high proportion of the open-chain form, which gives the aldehyde reaction. Model substances having different ring forms of different normal and deoxy sugars illustrate this point. In cells the aldehydo sugar is still attached to the purine and pyrimidine bases in the nucleoprotein, and the complex dye is therefore non-diffusible and locates precisely the nucleic acids. It was clear from Dr. Overend's remarks, however, how the action of lytic enzymes or over-hydrolysis by acids can give discrepancies in application of the reaction.

Mr. F. L. La Cour next discussed some aspects of his work at the John Innes Horticultural Institution on heterochromatin in plants. He explained briefly that the term 'heterochromatin' has been used to 
define specific chromosome segments which remain heavily stained and condensed at certain phases of the nucleal cycle. Heterochromatin is attached to the histone type of protein, whereas euchromatin is attached to more basic proteins. The amount of heterochromatin at various stages probably depends on competition with the euchromatin. The heterochromatin can be made particularly visible at metaphase by working at relatively low temperatures, for example, at $+5^{\circ}$, especially in cells from root tips. Using the method of working 'in the cold', Mr. La Cour has obtained a variety of results which he showed by micrographs and by numerous striking diagrams. In some plant species the chromosome segments are well defined, whereas in others they are either absent or the genes composing them are too minute to show up. Significant results have been obtained with various species of Fritillaria obtained from both the Now and the Old Worlds. In some of the New Worid species hetercchromatin is absent. The heterochromatin maps clearly enable one to detect species and give information on hybridity. Heterochromatin is probably concerned with the transfer of gene products to the cytoplasm.

In the final paper of the session, Mr. I. Leslie described recent work of the Biochemistry Department of the University of Glasgow on the role of the cell nucleus in the biochemistry of tissue growth. Based on Vendrely's postulate that the nucleus is a constant chemical entity in the cell, Mr. Leslie and his colleagues selected deoxyribonucleic acid as a constant measurable component (by phosphorus analysis) of the nucleus and are able to express results as increases in actual cell number and as variations in amounts per cell of the other cell components. This method gives a new and easily applied method of measuring growth, which is superior to methods based on measurement of changes of concentration per unit we ght.

The deoxyribonucleic acid content per nucleus varies with the pathological conditions ; for example, in fowl sarcoma the unit is 2.8 instead of the normal 1.4. Special applications of the analytical technique were then described. With the roller-tube tissueculture methods under aseptic conditions, it is possible to measure the changes in number of cells with time up to a maximum in a period of $96 \mathrm{hr}$. and to correlate these figures with increases in protein, phospholipid components, etc. Between 0 and $48 \mathrm{hr}$. the proteins and phospholipids increase most rapidly and are synthesized mainly before the deoxyribonucleic acid, and before cell division occurs. On the other hand, the ribonucleic acid content was shown to be greatest during cell multiplication. Some clearly marked changes are seen in the developing chick embryo, the most striking being the remarkable increase in muscle protein and acid-soluble phosphorus at the eighteenth day-presumably for the chick's purpose of extricating itself from the shell. Medical aspects in health and disease were then described, notably concerning glucuronidase in rat liver and for following changes in bone marrow components and in leukæmia and pernicious anæmia.

In the latter disease, there is a markedly higher content of deoxyribonucleic acid when double sets of chromosomes are seen and later the cells fail to divide. In chemically induced tumours and other abnormal growth cells, the failure to synthesize proteins can be seen in a clear fashion.

M. Stacey

\section{VIBRATIONAL STUDY OF THE WOOD USED FOR THE SOUND BOARDS OF PIANOS}

\author{
By EIICHI FUKADA
}

Kobayashi Institute of Physical Research, Kokubunji, Kitatama, Tokyo

HAVE measured the dynamic Young's modulus and the logarithmic decrement of spruce (in Japanese, Kuroezomatsu) which is used for the sound board of the piano; and I have investigated the difference in these physical quantities between suitable words for sound boards and unsuitable ones, as chosen by the piano maker by experience.

The method of experiment ${ }^{1}$ was the lateral vibration of a plate about $30 \mathrm{~cm}$. long, $2 \mathrm{~cm}$. wide and $0.3 \mathrm{~cm}$. thick. The Young's moduli were determined from the resonant frequencies of this sample. The logarithmic decrements were determined by measuring the total charge of the rectified damped electric current which was caused in the pick-up by the damped oscillation of the sample.

Suitable materials had widths of annual rings of about 1-2 mm.; unsuitable materials had rather large annual rings (about $3 \mathrm{~mm}$.). Two or three pieces of so-called red wood and rotted wood respectively were used. The fibres were orientated in the direction of length of the plate. Discrimination was easy by observing the appearance. The red wood is usually found in the lower part of the tree trunk. It is rather red coloured, hard and readily distorted. Rotted wood is wood which has begun to decompose.

Some of my results are shown in the accompanying graphs. Summarizing, I conclude that Young's modulus is higher for the suitable wood than for the unsuitable material, and that the logarithmic decre-

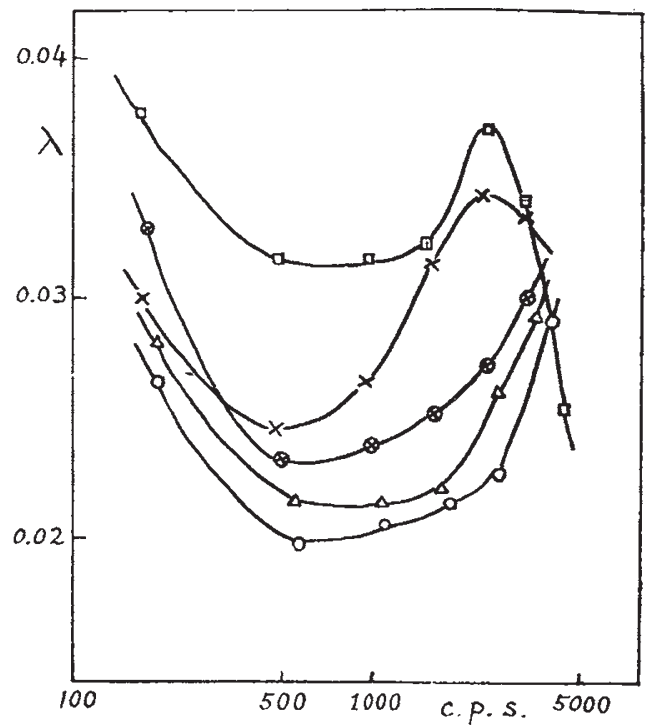

Fig. 1. Comparison of logarithmic decrement of suitable and unsuitable woods

O, 2-mm. annual ring; $E=1.22 \times 10^{11}$ dynes/cm.

$\Delta, 1-m m$. anuual riug, $E=1.18 \times 10^{21}$ dynes/cm. , larger width of annual ring: $E=1 \cdot 20 \times 10^{11}$ dynes $/ \mathrm{cm}$. $\times$, rotted wood $; E=0.8 \times 10^{11} \mathrm{dynes} / \mathrm{cm}$ 